\title{
An exploratory study of food safety and food handling: Examining ready-to-eat foods in independent delicatessen operations
}

\author{
Douglas Murray $^{1 *}$, Charles Feldman ${ }^{1}$, Lee Lee ${ }^{2}$, Casey Schuckers ${ }^{2}$ \\ ${ }^{1}$ Department of Health and Nutrition Sciences, Montclair State University, Montclair, USA \\ ${ }^{2}$ Department of Biology and Molecular Biology, Montclair State University, Montclair, USA \\ Email: ${ }^{*}$ murraydo@mail.montclair.edu
}

Received 2 January 2013; revised 4 February 2013; accepted 13 February 2013

\begin{abstract}
The US Center for Disease Control and Prevention (CDC, 2009) reports that each year 76 million cases of foodborne illness occur with over 300,000 people hospitalized and 5000 deaths. This study, Phase $I$ of a continuing study, identifies key areas for food safety improvement. This study is designed as an exploratory evaluation of independently owned and operated delicatessen operations, using Escherichia coli and Staphylococcus aureus as indicators to assess food handling and the public's risk for pathogenic contamination from commonly served ready-to-eat/take-away foods. The analysis consisted of a comprehensive strategy of laboratory testing of samples for pathogenic contamination, informal field observation of food handling procedures, and the examination of the most recent health inspection reports for each of the 18 operations visited. The deli turkey, cream cheese and lettuce were tested using bacteria indicator plates. The results showed widespread levels of contamination. Of the 54 samples tested for Escherichia coli, 26 showed positive results which are $\sim 45 \%$ for $E$. coli contamination. Of the 54 samples tested for Staphylococcus aureus, 31 showed positive results which are $\sim 57 \%$ for $S$. aureus contamination. One issue discovered while conducting the study was the lack of consistent uniform international standards of contamination tolerance levels. The informal field observations and health report analyses revealed widespread temperature violations and numerous instances of poor food handling. The study offers independent practitioners a strategy designed to improve their health inspections scores, food handling, and mitigation of operator liability. Independent operators traditionally do not enjoy the resources of centralized supervision and expert on-staff training; yet in aggregate they account for significant volume in
\end{abstract}

\footnotetext{
*Corresponding author.
}

both dollars and the quantity of product served. This study adds needed scrutiny to this important food niche.

Keywords: Food Safety; Food Handling; E. coli; S. aureus; Public Health; Ready-to-Eat Foods

\section{INTRODUCTION}

Traditionally, food safety research, both in the retail and foodservice sectors, has been geared toward chain operations. This occurs for many reasons. Studying one company with multiple outlets is efficient and the ability to compare like operations sharing a focused concept is appealing. Additionally, it seems intuitive that studying the largest organizations by virtue of their volume and geographical reach would be the most revealing and contribute the largest possible positive impact on food safety. This view is problematic on many levels. A meta-analysis of foodborne illness outbreaks conducted between 1993-1997 conducted by the Center for Disease Control [1] indicated that the highest percentage of outbreaks were associated with independent restaurants, delicatessens, and cafeterias. Other studies have found that large chain operations have distinct food safety advantages in economies of scale, resources, training, and equipment [2]. Philips et al. [3] further developed this reasoning as they postulated that large chain operators are considered the industry leaders, with corresponding high visibility and increased exposure and liability. Their findings revealed that these large companies have routinely used their financial resources to institute standardized practices and formalize food safety policies and procedures both as a means to protect their public reputation and as the basis for a legal defense strategy. It has been found that by adopting Hazard Analysis and Critical Control Points (HACCP) concepts, chains have developed a critical violation emphasis in their food safety approach as the most viable method of ensuring food safety, or at 
least minimizing foodborne illness outbreaks. While the numbers of health inspection violations between chain and independent foodservices have been shown to be similar, the critical violations that can most adversely affect food safety have been shown to be much lower in chain operations [4]. Chain operations have been found to have a statistically significant lower incidence of critical food handling violations, most likely due to the emphasis and resources allocated to controlling critical violations [5]. Conversely, independent operators have been shown to incur higher numbers of critical violations. The other significant advantage enjoyed by the chain operators is their ability to staff locations with trained/ certified kitchen managers [6]. Independent food services such as delicatessens do not possess corporate headquarters with highly trained and educated corporate management, consultants, or the ability to recruit hospitality and/ or culinary experts. Single owners or families with an entrepreneurial dream, but little in the way of industry experience or education, are often the operators of independent delicatessens. In small businesses just maintaining the normally long operating hours and keeping the business operating can exhaust all of ownerships energy and resources.

Foodborne illness is a significant contributor to human morbidity, mortality and the cost of health care. Readyto-eat foods can be especially high-risk since they are handled, served, and consumed without the application of antimicrobial processes such as heating prior to consumption. There are many food quality and safety indicator tests such as total plate count, coliforms, fecal coliforms, E. coli, Staphylococcus aureus, Listeria moncytognes etc. that can be used to test the efficacy of operational food handling. In this study E. coli is used as one indicator, it is a normal flora in the lower intestinal tract in humans and other warm-blooded animals and is abundant in human and animal feces. The presence of $E$. coli is a strong indication of poor quality food, food handling, and hygienic practices. In addition, it can be easily detected by its ability to ferment sugar. The second indicator used in this study is Staphylococcus aureus. It grows in a wide range of temperatures $\left(7^{\circ} \mathrm{C}\right.$ to $\left.48^{\circ} \mathrm{C}\right)$, and has low $\mathrm{pH}$, high salt and sugar content (up to $15 \%$ ). It produces heat stable enterotoxins and is a very common cause of food-borne illness. It is a normal flora in the nose, throat in human and animals. It can cause infection in cuts and other wounds and is easily passed indirectly from food handlers to contaminate ready-to-eat foods. The sources of food contamination are most often from improper handling of food such as contaminated hand contact or through airborne pathways such as, coughs, or sneezing [7]. The two indicators used in this study can provide insight on the quality of the food served and the hygiene of food handlers in independent deli operations.

\section{LITERATURE REVIEW}

Among the foods commonly served in delicatessens, Escherichia coli and Staphylococcus aureus bacteria have been particularly identified and isolated in purchased cooked and processed turkey, lettuce, and cream cheese products [7-12]. Staphylococcus aureus is a grampositive bacterium that is ubiquitous on human skin and is found in large amounts in animal and human fecal waste. Some strains of Staphylococcus aureus are capable of producing toxins in food. Escherichia coli is a gram-negative bacterium commonly present in the intestines and fecal waste of both animals and humans. In both cases, the organisms once ingested could produce toxins that are the actual cause of the foodborne illness symptoms that develop from the infection. Typical symptoms are nausea and vomiting with occasional abdominal cramping and diarrhea. Deaths and renal failure, though rare, have occurred amongst people with compromised immune systems such as, the chronically ill, children and the elderly. One serious concern for scientists is that laboratory testing has indicated that these toxins are capable of mutating and becoming resistant to antibiotics [1315]. Enterotoxins formed by these bacteria are temperature resistant, thus cooking does not mediate the pathogenic effects.

Though studies have indicated that environmental conditions such as irrigation, soil, and farm practices play a large role in food pathogen infection [16,17], most of the literature reviewed show clearly that proper food handling and personal hygiene are the critical improvement areas to protect the public. Fecal contamination of food from human handling, cross contamination, time and temperature procedure failures have been shown to be the major sources of pathogenic infection. The FDA has definitively identified fecal coliforms as an indicator of contamination in food [18]. Other studies have specifically linked poor time and temperature processes and controls to food borne illness outbreaks [19] with one study examining temperature and pathogen infection specifically to soft cheese holding and handling [20]. Certainly if proper temperature control of raw and ready to eat foods cannot be maintained, the opportunity for explosive bacterial growth is present. Several studies conducted internationally provide definitive evidence that insufficient decontamination actions are a primary cause of pathogenic contamination. Food handling and personal hygiene research has shown the most common factors in pathogenic contamination for food service operations to be: improperly cleaned or not cleaned knives, faucets, serving utensils, and cutting boards; cross-contamination between use with different products; and bare-handed food contact [21-23]. Even when gloves are worn they are often unchanged between food and cus- 
tomer contact with the result that the gloves themselves are found over time to be the cause of pathogen transfer [24]. As noted in a study published in the Nursing Standard [25] the simplest way to prevent the spread of disease from these coliforms is frequent and thorough hand washing and glove changing.

Seemingly then many cases of food borne disease could be easily prevented through greater emphasis on cleaning: hands, cutting boards, utensils, and any food contact surface; through utilizing gloves and changing them after each new task is completed; and the proper food storage and maintenance of refrigeration temperatures low enough to retard bacterial growth. One problem with the current system of public health policy is the overreliance on inspection and enforcement [26]. The research notes that placing the emphasis on inspection and enforcement can foster a climate of resistance and fear, where the Health Inspector is an outside authority whose function is to catch violators.

\section{MATRIALS AND METHODS}

\subsection{Sample Collection, Storage}

The food samples were collected from 18 delicatessens serving prepared and ready-to-eat foods for take out located in northern New Jersey, USA. Locations of the 18 delicatessens were conveniently picked with the proviso that they were independently operated, not part of a larger market, store, restaurant or chain, in a close proximity to Montclair State University (less than 30 minutes travel to the laboratory) and current health department inspection were on file and available to the investigators.

As indicated in the review of literature, turkey, lettuce, and cream cheese were selected as these foods are common to all the delis under study, are typically used daily and are handled repeatedly by multiple workers. The delicatessens were not informed that their food was being tested after purchase. Prior to data collection the field researchers were trained in sample collection procedures. The instructions included: observational keys and note taking, and rigorous sample collection and processing procedures. The observations were restricted to the customer/counter view as the anonymity of the researchers and the project precluded direct access to back of house operations. For each deli, a quarter pound of turkey, side of lettuce, and side of cream cheese $(>100 \mathrm{~g})$ was purchased individually wrapped either in a bag or a plastic container and then these samples were stored in sealed plastic bags. Temperatures of the samples were taken immediately after purchase using a thermometer that was heat-sterilized before contact. All of the samples were put on ice to prevent any growth of microorganisms during transport. Upon arrival, sample temperatures and time were again recorded. The samples were processed immediately upon arrival at the lab.

\subsection{Microorganism Testing}

One gram was weighed out from each sample and $9 \mathrm{ml}$ of sterile diluents; Butterfield's phosphate buffer or distilled water was added to homogenize the food for 5 minutes. $\mathrm{PH}$ of the samples was measured and titrated with either $1 \mathrm{~N} \mathrm{NaOH}$ or I $\mathrm{N} \mathrm{HCl}$ to $\mathrm{pH}$ between 6.6 and 7.2. Place $3 \mathrm{M}^{\mathrm{TM}}$ Petrifilm ${ }^{\mathrm{TM}}$ E. coli/coliform count plates or $3 \mathrm{M}^{\mathrm{TM}}$ Petrifilm ${ }^{\mathrm{TM}}$ Staphylococcus aureus express count plates on a level surface. On each plate the top film was lifted and $1 \mathrm{~mL}$ of blended sample was placed onto the center of the bottom film of each plate. The top film was carefully rolled down to avoid entrapping air bubbles. With the flat side down, a spreader was placed on the top film over the inoculums and gentle pressure was applied to the spreader to distribute the inoculums over the circular area of the test plate before a gel is formed. Care was taken to not twist or slide the spreader. The sample was allowed to sit and wait a minimum of one minute for the gel to solidify. The plates were placed in the incubator at $35^{\circ} \mathrm{C}$ with the clear side up in stacks of up to 20. S. aureus plates were allowed to incubate for 24 hours and then colonies were counted. The turkey E. coli plates were allowed to incubate for 24 hours, the lettuce and cream cheese were incubated for 48 hours then the colonies were counted.

The Association of Analytical Communities (AOAC) Research Institute (USA)-certified $3 \mathrm{M}^{\mathrm{TM}}$ Petrifilm ${ }^{\mathrm{TM}} E$. coli/coliform count plates and Staphylococcus aureus express count plates were used to record the number of colonies of each of the type of microorganism in the samples. Each sample was tested for E. coli and $S$. aureus. Plates were taken out of closed packages at time experiment. The E. coli/coliform count plates detected both $E$. coli and coliforms and need to be incubated for 24 - 48 hours at $35^{\circ} \mathrm{C}$. (depending on food type). E. coli was seen to be the dark blue colonies, which were easy to count, by human eye. These plates consist of a polyester film, polystyrene foam, transfer adhesive, polypropylene film, guar gum, nutrients, hinge tape, lactose, and pancreatic digest of gelatin. The staph express plates only detected $S$. aureus. They were incubated for 24 hours at $35^{\circ} \mathrm{C}$. The colonies show up as a red-violet color. The ingredients include nutrient media coated on paper with foam retaining dam and film cover sheet. For each test, positive controls were used. All equipment used was sanitized after each use to make sure there was no cross contamination during the testing.

\section{RESULTS}

The total plate counts of Staphylococcus aureus and Escherichia coli from the 18 different delicatessens are 
shown in Table 1. Microorganism contamination tests show the results from the testing of food samples for the presence of Staphylococcus aureus (Table 1). There are 11 out of 18 turkey samples, 12 out of 18 lettuce samples and 8 of 18 cream cheese samples that tested positive for
Staphylococcus aureus. Of the 54 samples tested for Staphylococcus aureus, 31 were found to have at least 10 colonies of contamination, the \% of contamination samples is $\sim 57 \%$ as a whole. Contamination of the turkey, lettuce, and cream cheese were $\sim 61 \%, \sim 66 \%, \sim 44 \%$ re-

Table 1. Total plate count of E. coli on samples collected at each location with temperatures taken at point of collection (in Fahrenheit) and selected Health Department inspection report comments.

\begin{tabular}{|c|c|c|c|c|c|c|c|c|c|c|}
\hline \multirow[t]{2}{*}{ SITE } & \multicolumn{2}{|c|}{$\begin{array}{l}\text { Turkey } \\
\text { Plate count } \\
\text { cells/grams }\end{array}$} & \multirow[t]{2}{*}{ TEMP } & \multicolumn{2}{|c|}{$\begin{array}{c}\text { Lettuce } \\
\text { E. coli (cells/gram) }\end{array}$} & \multirow[t]{2}{*}{ TEMP } & \multicolumn{2}{|c|}{$\begin{array}{c}\text { Cream } \\
\text { Cheese } \\
\text { (cells/gram) }\end{array}$} & \multirow[t]{2}{*}{ TEMP } & \multirow[t]{2}{*}{$\begin{array}{l}\text { Selected Health Department } \\
\text { Comments }\end{array}$} \\
\hline & E. coli & S. aureus & & E. coli & S. aureus & & E. coli & S. aureus & & \\
\hline 1 & 30 & 20 & $42^{\circ}$ & 0 & 10 & $50^{\circ}$ & 30 & 0 & $42^{\circ}$ & $\begin{array}{l}\text { Out of compliance for } 11 \text { out of } 52 \text { risk factors, } \\
\text { including: not wearing gloves, cross } \\
\text { contamination, improper holding temperatures, } \\
\text { fruit flies, no thermometers, food } \\
\text { accumulations, no sanitizing test kit. }\end{array}$ \\
\hline 2 & 30 & 50 & $38^{\circ}$ & 0 & 20 & $28^{\circ}$ & 30 & 0 & $39^{\circ}$ & $\begin{array}{l}\text { Out of compliance for } 6 \text { out of } 52 \text { risk factors, } \\
\text { including: not enough soap available for hand } \\
\text { washing, improper cold-holding temperatures, } \\
\text { use of gloves without hand wash. }\end{array}$ \\
\hline 3 & 0 & 0 & $56^{\circ}$ & 0 & 0 & $56^{\circ}$ & 20 & 0 & NA & $\begin{array}{l}\text { Four comments on report, including non-use of } \\
\text { gloves. }\end{array}$ \\
\hline 5 & 270 & 550 & $70^{\circ}$ & 970 & 520 & $72^{\circ}$ & 40 & 0 & $73^{\circ}$ & Gloves not used. \\
\hline 6 & 0 & 30 & $70^{\circ}$ & 3600 & 10 & $73^{\circ}$ & 40 & 60 & $73^{\circ}$ & Cleaning is required throughout establishment. \\
\hline 7 & 0 & 20 & $70^{\circ}$ & 0 & 10 & $60^{\circ}$ & 10 & 80 & $56^{\circ}$ & Gloves not used. \\
\hline 8 & 10 & 10 & $70^{\circ}$ & 50 & 60 & $70^{\circ}$ & 50 & 10 & $71^{\circ}$ & $\begin{array}{l}\text { Potentially Hazardous Foods (PHF) not } \\
\text { maintained at refrigeration temperatures. }\end{array}$ \\
\hline 9 & 520 & 0 & $60^{\circ}$ & 320 & 0 & $50^{\circ}$ & 0 & 0 & $60^{\circ}$ & $\begin{array}{l}\text { Food contact surfaces not properly sanitized, } \\
\text { improper cooling. }\end{array}$ \\
\hline 10 & 0 & 10 & $71^{\circ}$ & 0 & 40 & $70^{\circ}$ & 0 & 0 & $69^{\circ}$ & $\begin{array}{l}\text { Multiple PHFs in sandwich prep unit with poor } \\
\text { product temperature } 51-71^{\circ} \mathrm{F} \text {. }\end{array}$ \\
\hline 11 & 0 & 60 & $46^{\circ}$ & 30 & 20 & $48^{\circ}$ & 0 & 0 & $50^{\circ}$ & Walk-in refrigeration $45^{\circ} \mathrm{F}$. \\
\hline 12 & 0 & 0 & $65^{\circ}$ & 0 & 0 & $70^{\circ}$ & 0 & 0 & $58^{\circ}$ & $\begin{array}{l}\text { Out of compliance for } 10 \text { out of } 52 \text { risk factors, } \\
\text { including: Hand sink with a dirty dish inside, } \\
\text { hand sink with no soap or paper towels, raw } \\
\text { chicken stored above ready-to-eat foods, no } \\
\text { hair restraint. Improper cold-holding for tuna } \\
\text { salad- } 45^{\circ} \text {; cream cheese- } 45^{\circ} \text {; raw chicken- } \\
45^{\circ} \text {; deli ham- } 45^{\circ} \mathrm{F} \text {. }\end{array}$ \\
\hline 13 & 0 & 70 & $51^{\circ}$ & 4500 & 80 & $42^{\circ}$ & 0 & 20 & $52^{\circ}$ & $\begin{array}{l}\text { Out of compliance for } 12 \text { out of } 52 \text { risk factors, } \\
\text { including: storage of ingredients on floor, } \\
\text { improper cold holding temperatures, } \\
\text { equipment worn or in disrepair. }\end{array}$ \\
\hline 14 & 0 & 0 & $61^{\circ}$ & 580 & 210 & $79^{\circ}$ & 30 & 270 & $69^{\circ}$ & Eggs stored over ready-to-eat foods. \\
\hline 15 & 0 & 3640 & $48^{\circ}$ & 0 & 10 & $43^{\circ}$ & 0 & 250 & $41^{\circ}$ & $\begin{array}{l}\text { Live fly, accumulation of dried food scraps on } \\
\text { non-food contact surface of deli slicer. }\end{array}$ \\
\hline 16 & 0 & 0 & $41^{\circ}$ & 30 & 0 & $42^{\circ}$ & 0 & 0 & $42^{\circ}$ & $\begin{array}{l}\text { [Most current report available-3 years old.] } \\
\text { Hand washing, hair restraints, food handler's } \\
\text { certificate needed. }\end{array}$ \\
\hline 17 & 0 & 30 & $40^{\circ}$ & 10 & 80 & $38^{\circ}$ & 0 & 0 & $41^{\circ}$ & Hot water $87^{\circ}$, milk case $44^{\circ}$, deli case $45^{\circ}$. \\
\hline 18 & 0 & 0 & $46^{\circ}$ & 60 & 0 & NA & 0 & 10 & $49^{\circ}$ & Okay, no comments. \\
\hline \multicolumn{11}{|c|}{ Percent of Delis with Contamination } \\
\hline & $\begin{array}{c}33 \% \\
(6)\end{array}$ & $\begin{array}{l}61 \% \\
(11)\end{array}$ & & $\begin{array}{l}61 \% \\
(11)\end{array}$ & $\begin{array}{l}66 \% \\
(12)\end{array}$ & & $\begin{array}{c}50 \% \\
(9)\end{array}$ & $\begin{array}{l}44 \% \\
(8)\end{array}$ & & \\
\hline
\end{tabular}


spectively. The CFU (Colony Counting Unit) per gram for $S$. aureus under $10^{2}$ is Satisfactory, range from $10^{2}$ to $10^{3}$ is Marginal and from $10^{3}$ to $10^{4}$ is Unsatisfactory and above $10^{4}$ is Potential Hazardous. Location 15 showed the most turkey Staphylococcus aureus contamination with $3.64 \times 10^{3}$ cells/gram. This location according to the Microbiological Quality (CFU)/ gram from FDA is Unsatisfactory. The next location, \#5 had 550-cells/per gram of food and it is classified as Marginal quality. Locations 1, 2, 6, 7, 8, 10, 11, 13, and 17 also were found to have Staphylococcus aureus contamination in the turkey; these locations fall in the satisfactory category. Location 5 was found to have the highest amount of Staphylococcus aureus in lettuce with 520-cells/per gram of food. Location 14 was found to have 220 cells /per gram of lettuce. Both location 5 and 14 are categorized as Marginal. Locations 13 and 17 had 80-cells/per gram of lettuce. Locations 1, 2, 6, 7, 8, 10, 11, and 15 had lettuce contamination but not as much as the other locations stated above and are categorized as Satisfactory. Cream cheese contamination had the least amount of locations with contamination but locations 14 and 15 had high amounts, 270 and 250-cells/per gram of cream cheese respectively and are considered Marginal. Locations 3, 6, 7, 8, 13, and 18 were found to have Staphylococcus aureus contamination as well in the cream cheese. Locations 4, 9, 12, 16 and 18 had no Staphylococcus aureus in any of the samples, and suggested that their food quality and handling practices were effective.

The CFU (Colony Counting Unit) per gram for E. coli under 3 is Satisfactory, between 13 to $10^{2}$ is Marginal and above $10^{2}$ is Unsatisfactory and Pathogenic strain of E. coli should be absent under the category of Potential Hazardous. The summary of the total plate count for Escherichia coli is also shown in Table 1. Of the 54 samples tested for $E$. coli, 26 were found to have at least 10 colonies of contamination ( $\sim 8 \% \%) .6$ samples of turkey ( 33\%), 11 samples of lettuce ( 61\%), and 9 samples of cream cheese $(\sim 50 \%)$ were contaminated with Escherichia coli. All these locations fall below the Satisfactory level. The turkey samples had the least amount of locations with contamination. Location 9 had the highest $E$. coli count, 520-cells/ per gram of turkey. Locations 4 and 5 had a high amount, 190 and 270-cells/ per gram of turkey respectively. All these locations are designated as Unsatisfactory in food quality. Escherichia coli contamination in turkey was also found in locations 1,2 , and 8 . There was a high level of Escherichia coli found in lettuce. Locations 6 and 13 had the highest amount, $3.6 \times$ $10^{7}$ and $4.5 \times 10^{3}$ cells/ gram respectively which are very high and should be considered dangerous. Location 5 was found to have 970-cells/ per gram of lettuce, which is considered, Unsatisfactory. Locations $4,8,11,14,16$, 17, and 18 were found to have Escherichia coli con- tamination in the lettuce as well. Half of the locations were found to have Escherichia coli contamination in their cream cheese. Location 4 had the highest amount of contamination with 100 cells/ per gram of cream cheese, which is considered to be Unsatisfactory. Locations 1, 2, 3, 5, 6, 7, 8, and 14 also were found to have Escherichia coli contamination in the cream cheese. Locations 10, 12 and 15 have no Escherichia coli in any of the samples, and suggested that their food handling practices were effective.

\section{Health Reports and Informal Field Observations}

Only one of the 18 delicatessens studied had a health department report without violations (Table 1). Eleven of the delis studied had been cited for improper cold holding temperature control. Five of the reports noted barehanded contact with ready to eat food.

As the samples were collected there was the opportunity to observe the food handling behavior and processes in the field. In 14 of the 18 locations observed there were food-handling issues such as hand to hair and/or mouth to food contact and barehanded food contact. In operations where gloves were worn the sample collectors noted that the gloved hands were never washed or the gloves changed as the employee moved from food handling to cash handling to customer contact. Some representative exemplars follow:

"employee wearing gloves was observed eating in the service area. Upon finishing eating the employee returned to work, without changing gloves or washing, and began serving customers and handling ready to eat food"

"the food handler was not wearing gloves and touched the turkey, cream cheese, and lettuce barehanded and in sequence without hand washing, the employee then completed the cash transaction and moved on to serve the next customer still without gloves or hand sanitation"

"the food handler wore one glove but sliced the turkey and handled the lettuce with both hands. While dispensing the cream cheese some fell from the serving utensil onto the work counter where the sliced turkey had been placed prior to wrapping, the employee picked up the cheese barehanded and placed it in the takeout container. The employee proceeded to conduct the cash transaction using both the gloved and ungloved hand then moved on to serve the next customer. At no time during the observation period was any work counter sanitized; hand washing and glove changing were also not observed throughout the observation period".

Cutting boards were routinely not sanitized between contacts with different foods. In 15 of the 18 delis studied, the food sample temperatures, taken immediately upon purchase by the investigator, were found to be well above acceptable temperature ranges for the safe storage 
Table 2. Comparison of international standards for microbiological quality.

\begin{tabular}{ccccccc}
\hline & \multicolumn{2}{c}{ United Kingdom } & \multicolumn{2}{c}{ Australia } & \multicolumn{2}{c}{ United States } \\
\cline { 2 - 6 } & E. coli & Staphylococci & E. coli & Staphylococci & E. coli & Staphylococci \\
\hline Good & $<20$ & $<20$ & $<3$ & $<10^{2}$ & $<3$ & $<10^{2}$ \\
Marginal & 20 to $\leq 10^{2}$ & 20 to $10^{4}$ & 3 to $<10^{2}$ & $10^{2}$ to $<10^{3}$ & $3-100$ & $10^{2}$ to $10^{3}$ \\
Unsatisfactory & $>10^{2}$ & $>10^{4}$ & $\geq 10^{2}$ & $10^{3}$ to $<10^{4}$ & $>100$ & $10^{3}$ to $10^{4}$ \\
Hazardous & N/A & N/A & N/A & $\geq 10^{4}$ & $>10^{4}$ \\
\hline
\end{tabular}

Source: NSW Food Authority (2009, July). Microbiological Quality Guide for Ready-To-Eat Food and US Food and Drug Administration.

of refrigerated items. These findings coincided with temperature-abuse and food handling violations on most of recent health inspection report obtained for each operation studied.

\section{DISCUSSION}

As can be seen from the results it is much more likely the foods taken from the independent food service operations in this study are more likely to be contaminated than not. Most fecal coli form ingestion produces mild symptoms that often go unreported, thus unrecorded. Therefore, it is possible that conditions noted in this study similarly resulted in unreported illness. As the different pathogenic strains transform and become increasingly resistant strategies to promote and improve food handling and small operator food safety education is critical. In addition to underreporting, the lack of consistent international tolerance levels contributes to the problem. The FDA does provide guideline levels for determining the microbiological quality of ready-to-eat food, as does New Zealand, Australia, and the United Kingdom. The standards however, are not consistent (see Table 2) and thus a universal benchmark has yet to be developed.

The fact that 15 of 18 delis had improper cold-holding temperatures and only 1 of the 18 was violation free in their health inspection reports strongly indicates a serious threat to consumers and a failure in public health policy. It seems that some chain operators have used their resources to develop more effective strategies to protect themselves and their customers from food borne disease. Public health departments and policy makers must address, at minimum, the disparity of potential food safety risk between large chains and independent operators. One way would be to following the path already identified by the larger operations to increase food safety. Increasing training and education over inspection and enforcement would be a significant first step in leveling the field. The current system of inspection/violation/citation creates an adversarial relationship that can often accrue between inspectors and operators. Shifting the relationship from inspection to education might give the independent operator an ability to duplicate the chain's results in inspection scores. While independent foodservice managers in New Jersey and other states are already required to have a food handlers training certification, more advanced level training for all independent food service employees with an emphasis on critical violations seems to be the obvious direction since this strategy of critical violation control and training and certification has proved so effective for chain operators. Temperature control and personal hygiene issues, while the culprits in this study, seem to be the type of problems that are most easily solved and there should be no excuse for not attacking this issue.

\section{FUTURE RESEARCH}

This preliminary study provides us much important information and a solid direction for future research. The phase II study will include more tests for potential pathogen detection such as Salmonella and Listeria etc. In addition, advanced $E$. coli study to identify specific pathogen such as E. coli O157:H7 using available micro identification kits or PCR (Polymerase Chain Reaction) will be carried out. The phase II research will concentrate on reducing the limitations inherent in this investigation. A larger number of operations studied would improve the generalizability of the study results. A larger sample would also allow statistical analysis of differences that might be identified by such mediating factors as dollar volume, number of employees, form of ownership/management, and geographical location. If policy changes were attempted, adding a longitudinal study would allow for the tracking of results gained from the policy adjustments.

Future research designed to develop consistent national and international standards would be of great benefit. Not only for the clarification of tolerance levels regardless of jurisdiction, but to gain a common understanding that would allow researchers everywhere to be using the same metrics in evaluating the safety of readyto-eat foods across borders.

\section{REFERENCES}

[1] Olsen, S., MacKinnon, L., Goulding, J., Bean, N. and Slutsker, L. (2000) Surveillance for foodborne disease out- 
breaks-United States 1993-1997. MMWR CDC Surveillance Summaries, 49, 1-62.

[2] Frash, R., Alamanza, B. and Stahura, J. (2003) Assessments of food safety risk: A case study in Marion county, Indiana. International Journal of Hospitality \& Tourism Administration, 4, 25-44. doi:10.1300/J149v04n04_02

[3] Phillips, M., Elledge, B., Basara, H., Lynch, R. and Boatright, D. (2006) Recurrent critical violations of the food code in retail food service establishments. Journal of Environmental Health, 68, 24-30.

[4] Murphy, K., DiPietro, R., Kock, G. and Lee, J. (2011) Does mandatory food safety training and certification for restaurant employees improve inspection outcomes? International Journal of Hospitality Management, 30, 150156. doi:10.1016/j.ijhm.2010.04.007

[5] Green, L. and Selman, C. (2005) Environmental health specialists' practices and beliefs concerning restaurant inspections. Paper presented at the 92 Annual International Association for Food Protection, Baltimore.

[6] Hedberg, C., Smith, S. and Kirkland, E. (2006) Systematic environmental evaluations to identify food safety differences between outbreak and non-outbreak restaurants. Journal of Food Protection, 69, 2697-2702.

[7] Center for Disease Control (2012) General information. http://www.cdc.gov/foodsafety

[8] Ackers, M., Mahon, B., Leahy, E., Goode, B., Damrow, T., Hayes, P. and Slutsker, L. (1998) An outbreak of Escherichia coli O157:H7 infections associated with leaf lettuce consumption. Journal of Infectious Diseases, 177, 1588-1593. doi:10.1086/515323

[9] Kaneko, K., Hayashidani, H., Ohtomo, Y., Kosuge, J., Kato, M., Takahashi, K. and Oga-Wa, M. (1999) Bacterial contamination of ready-to-eat foods and fresh products in retail shops and food factories. Journal of Food Protection, 62, 644-649.

[10] Sharma, M., Patel, J., Conway, W., Ferguson, S. and Sulakvelidze, A. (2009) Effectiveness of bacteriophages in reducing Escherichia coli O157:H7 on fresh-cut cantaloupes and lettuce. Journal of Food Protection, 72, 14811485.

[11] Sivapalasingam, S., Friedman, C., Cohen, L. and Tauxe, R. (2004) Fresh produce: A growing cause of outbreaks of foodborne illness in the United States. Journal of Food Protection, 67, 2342-2353.

[12] Soriano, J., Rico, H., Molto, C. and Manes, J. (2001) Incidence of microbial flora in lettuce, meat, and Spanish potato omelet from restaurants. Food Microbiology, 18, 159-163. doi:10.1006/fmic.2000.0386

[13] Brzuszkiewicz, E., Thumer, A., Schuldes, J., Leimbach, A., Liesegang, H., Meyer, F. and Daniel, R. (2011) Genome sequence analyses of two isolates from the recent Escherichia coli outbreak in Germany reveal the emergence of a new pathotype: Entero-Aggregative-Hemorrhagic Escherichia coli (EAHEC). Archives of Microbiology, 193, 883-891. doi:10.1007/s00203-011-0725-6
[14] Gould, D. (2011) MRSA: Implications for hospitals and nursing homes. Nursing Standard, 25, 47-56.

[15] Rhee, C. and Woo, G. (2010) Emergence and characterization of foodborne methicillin-resistant staphylococcus in Korea. Journal of Food Protection, 73, 2285-2290.

[16] Barker-Reid, F., Harapas, D., Engleitner, S., Kreidl, S. and Faggian, R. (2009) Persistence of Escherichia coli on injured iceberg lettuce in the field, overhead irrigated with contaminated water. Journal of Food Protection, 72, 458-464.

[17] Franz, E. and Vanruggen, A. (2008) Ecology of E. coli O157:H7 and Salmonella enterica in the primary vegetable production chain. Critical Reviews in Microbiology, 34, 143-161. doi:10.1080/10408410802357432

[18] Feng, P., Weagant, S., Grant, M. and Burkhardt, W. (2012) Bacteriological analytical manual chapter 4 enumeration of Escherichia coli and the coliform bacteria. http://www.fda.gov/food/scienceresearch/laboratorymeth ods/bacteriologicalanalyticalmanualbam/ucm064948.htm

[19] Kim, H., Griffiths, M., Fazil, A. and Lammerding, A. (2009) Probabilistic risk model fro Staphylococcal intoxication from pork-based food dishes prepared in food service establishments in Korea. Journal of Food Protection, 72, 1897-1908.

[20] Tan, A., Beaton, S., Dimovski, K., Hogg, G., di Paola, V. and Haines, H. (2008) Pathogen survival in portioned retail soft cheeses. Australian Journal of Dairy Technology, 63, 39-44.

[21] Clayton, D. and Griffith, C. (2004) Observation of food safety practices in catering using notational analysis. British Food Journal, 106, 211-227. doi:10.1108/00070700410528790

[22] Kennedy, J., Nolan, A., Gibney, S., O’Brian, S. and MacMahon, M. (2011) Determinants of cross-contamination during home food preparation. British Food Journal, 113, 280-297. doi:10.1108/00070701111105349

[23] Rodriguez, M., Valero, A., Posada-Izquierdo, G., Carrasco, E. and Zurera, G. (2011) Evaluation of food handler practices and microbiological status of ready-to-eat foods in long term care facilities in the Andalusia region of Spain. Journal of Food Protection, 74, 1504-1512. doi:10.4315/0362-028X.JFP-10-468

[24] Lahou, E., Jacxsens, L., Vanlandeghem, F. and Uyttendaele, M. (2012) Microbiological performance of a food safety management system in a food service operation. Journal of Food Protection, 75, 706-716. doi:10.4315/0362-028X.JFP-11-260

[25] Tompkins, B. (2011) E. coli infections. This practice profile is based on NS537 Gould, G. (2010) Causes and treatment of Escherichia coli infections. Nursing Standard, 25, 51-60.

[26] Reske, K., Jenkins, T., Fernandez, C., VanAmber, D. and Hedberg, C. (2007) Beneficial effects of implementing an announced restaurant inspection program. Journal of Environmental Health, 69, 27-34. 